\title{
Short communication: Field fertility in Holstein bulls: Can type of breeding strategy (artificial insemination following estrus versus timed artificial insemination) alter service sire fertility?
}

\author{
E. O. S. Batista, ${ }^{* 1}$ L. M. Vieira, ${ }^{* 1}$ M. F. Sá Filho, ${ }^{*}$ P. D. Carvalho, $†$ H. Rivera, $\ddagger$ V. Cabrera, $†$ M. C. Wiltbank, $\dagger$ \\ P. S. Baruselli, ${ }^{*}$ and A. H. Souzat $\S^{2}$ \\ *Department of Animal Reproduction, Faculdade de Medicina Veterinaria e Zootecnia, Universidade de São Paulo, São Paulo, SP, 05508270, \\ Brazil \\ †Department of Dairy Science, University of Wisconsin, Madison 53706 \\ $\ddagger$ Accelerated Genetics, Baraboo, WI 53913 \\ $\S$ Ceva Sante Animale, Libourne, 33500, France
}

\begin{abstract}
The aim of this study was to compare pregnancy per artificial insemination $(\mathrm{P} / \mathrm{AI})$ from service sires used on artificial insemination after estrus detection (EAI) or timed artificial insemination (TAI) breedings. Confirmed artificial insemination outcome records from 3 national data centers were merged and used as a data source. Criteria edits were herd's overall P/AI within 20 and $60 \%$, a minimum of 30 breedings reported per herd-year, service sires that were used in at least 10 different herds with no more than $40 \%$ of the breedings performed in a single herd, breeding records from lactating Holstein cows receiving their first to fifth postpartum breedings occurring within 45 to $375 \mathrm{~d}$ in milk, and cows with 1 to 5 lactations producing a minimum of $6,804 \mathrm{~kg}$. Initially $1,142,859$ breeding records were available for analysis. After editing, a subset of the data $(\mathrm{n}=857,539)$ was used to classify breeding codes into either EAI or TAI based on weekly insemination profile in each individual herd. The procedure HPMIXED of SAS was used and took into account effects of state, farm, cow identification, breeding month, year, parity, days in milk at breeding, and service sire. This model was used independently for the 2 types of breeding codes (EAI vs. TAI), and service sire P/AI rankings within each breeding code were performed for sires with $>700$ breedings (94 sires) and for sires with $>1,000$ breedings $(\mathrm{n}=56$ sires $)$ following both EAI and TAI. Correlation for service sire fertility rankings following EAI and TAI was performed with the PROC CORR of SAS. Service sire P/AI rankings produced with EAI and TAI were 0.81 (for sires with $>700$ breedings) and 0.84 (for sires with $>1,000$ breedings). In ad-
\end{abstract}

Received June 27, 2015.

Accepted November 23, 2015.

${ }^{1}$ The first two authors contributed equally to this work.

${ }^{2}$ Corresponding author: ahsouza76@gmail.com dition, important changes occurred in service sire $\mathrm{P} / \mathrm{AI}$ ranking to EAI and TAI for sires with less than 10,000 recorded artificial inseminations. In conclusion, the type of breeding strategy (EAI or TAI) was associated with some changes in service sire $\mathrm{P} / \mathrm{AI}$ ranking, but ranking changes declined as number of breedings per service sire increased. Future randomized studies need to explore whether changes in $\mathrm{P} / \mathrm{AI}$ ranking to EAI versus TAI are due to specific semen characteristics. Key words: sire fertility, conception rate, dairy cow

\section{Short Communication}

In commercial dairy herds worldwide, detection of behavioral estrus is performed by visual observation following the am/pm (before/after midday) AI routine (Trimberger, 1948), AI once a day in association to daily tail chalk (Nebel et al., 1994), utilizing heat-mount detectors such as Kamars (Kamar Inc., Steamboat Springs, CO), or even electronic activity meters (Caraviello et al., 2006; Michaelis et al., 2013). However, none of these strategies are accurate to predict the timing of ovulation following estrus detection even in cows equipped with more advanced electronic activity devices (Valenza et al., 2012). For example, Valenza et al. (2012), using advanced estrus activity devices equipped with accelerometers (Heatime, SCR Engineers Ltd.) and evaluating the time of ovulation with frequent ultrasound exams, reported that in a twice-daily breeding program the AI-to-ovulation interval varied from -12 to $26 \mathrm{~h}$. As a result, Valenza et al. (2012) observed that approximately $25 \%$ of the cows were bred too early in relation to ovulation time ( $>12 \mathrm{~h}$ before ovulation), whereas a further $20 \%$ of the cows were bred too late (after ovulation had occurred). These findings are in agreement with several other studies describing the great variation in the interval from estrus to ovulation in cattle (Hernández-Cerón et al., 1993; Saumande and Humblot, 2005; Bloch et al., 
2006; Hockey et al., 2010; Valenza et al., 2012). Because of this wide variation, numerous research groups have evaluated the most appropriate timing of artificial insemination relative to the onset of estrous, ovulation, or both, in cows (Rankin et al., 1992; Dransfield et al., 1998; Pursley et al., 1998; Roelofs et al., 2006; Hockey et al., 2010; Sales et al., 2011; Valenza et al., 2012). They all seem to agree that this wide variation in AIto-ovulation interval may compromise oocyte fertilization when cows are breed too early and lower embryo quality if cows are bred too late, which in turn will affect pregnancy per AI (P/AI; Hockey et al., 2010).

Timed AI (TAI) programs such as the Ovsynch protocol use a combination of $\mathrm{GnRH}$ and $\mathrm{PGF}_{2 \alpha}$ to control timing of ovulation (Pursley et al., 1995). These synchronization programs have been adopted at different degrees by most US dairies (Caraviello et al., 2006; Souza et al., 2013). Synchronization protocols for TAI will cause most cows to ovulate synchronously within a short 8 to $12 \mathrm{~h}$ window (Pursley et al., 1995; Souza et al., 2009), making the time of ovulation more predictable and creating an opportunity to improve AI-to-ovulation intervals in relation to AI performed following detection of estrus (EAI).

The optimal time at which insemination should take place relative to ovulation appears to depend on the fertility lifespan of spermatozoa and the viable lifespan of the oocyte in the female genital tract after ovulation occurs (Dransfield et al., 1998; Roelofs et al., 2006; Hockey et al., 2010; Gosálvez et al., 2011). Accordingly, if AI takes place at long intervals before ovulation, sires with improved semen quality would probably be less likely to have reduced conception results due to their longer sperm cell lifespan as compared with sires with shorter lifespan in the female tract (MacMillan and Watson, 1975; Hockey et al., 2010). Consequently, assuming the variation in semen quality traits from different sires and the possibility of precisely control timing of ovulation with timed AI protocols, it is reasonable to hypothesize that some service sires may yield results of $\mathrm{P} / \mathrm{AI}$ that may differ if $\mathrm{AI}$ is performed after EAI or following TAI programs. Thus, the main objective of this study was to compare P/AI from same service sires used both following AI after EAI and TAI.

Confirmed AI outcome records from 3 US data centers (AgSource, Verona, WI; Agritech Analytics, Visalia, CA; and Data Records Management Services, Raleigh, NC) were merged and used as data sources. It is important to clarify that this evaluation is not genetic but phenotypic, and criteria edits to the whole data set included only breedings with confirmed conception results that took place in US Holstein herds from January 1, 2008, to April 30, 2012, only herds with overall $\mathrm{P} / \mathrm{AI}$ within 20 and $60 \%$, a minimum of 30 breedings reported per herd, sires that were used in at least 10 different herds with no more than $40 \%$ of the breedings performed in a single herd, breeding records from lactating Holstein cows only that received their first to fifth postpartum breedings occurring within 45 to 375 DIM, and only cows that had 5 or less lactations producing a minimum of $6,804 \mathrm{~kg}$. After editing, a total of 857,539 breeding records were used and classified into breeding codes as either EAI or TAI based on weekly insemination profile in each individual herd. First, regardless of the days of the week, breedings that took place before 60 DIM were all assumed to have occurred following estrus. Second, a subset of farms ( $\mathrm{n}=$ 10) with known breeding codes was used to determine the distribution of breeding events occurring after EAI and TAI (Figure 1). Thus, we used a subset of 10 herds in which we had access to the actual breeding codes (Ovsynch or Estrus) recorded in the farm's management software to validate the classification method used to categorize breedings into EAI or TAI. Herds breeding cows only following estrus detection would have AI events occurring more evenly throughout all days of the week and, thereby, should have approximately $14 \%$ (100\% of the breedings divided by the 7 $\mathrm{d}$ of the week) of the cows being bred at any given day of the week. In contrast, herds utilizing TAI would have a sharp increase in proportion of AI that take place at specific days of the week. Thus, we calculated the standard deviation of the weekly breeding distribution for each individual herd, then assumed that TAI breedings within a herd were those that took place in days of the week with more than 2 standard deviations above the farm's daily average number of breedings, which is $14.3 \%$ (or 100\%/7). For example, a herd that has the breeding distribution as follows: Monday $=32$ AI; Tuesday $=40$ AI; Wednesday $=27$ AI; Thursday $=145$ AI; Friday $=47$ AI; Saturday $=21$ AI; Sunday $=15 \mathrm{AI}$, would have in terms of percentage of weekly breeding distribution as follows: Monday $=9.8 \%$; Tuesday $=12.2 \%$; Wednesday $=8.3 \%$; Thursday $=44.3 \%$; Friday $=14.4 \%$; Saturday $=6.4 \%$; Sunday $=4.6 \%$. Thus, average daily percentage of AI would be $14.3 \%$ (a constant parameter across herds using EAI only), and the standard deviation for percentage of breedings would be $13.7 \%$. Then, 2 times the SD (13.7\%) would be $27.3 \%$ plus $14.3 \%$ is $41.6 \%$. In this case, the breedings performed on Thursdays are $44.3 \%$ of total breedings, which is greater than $41.6 \%$, and those breedings performed on Thursday were then classified as TAI as shown in Figure 1. This criteria was then applied to all herds in the database. It is important to highlight that the $2 \mathrm{SD}$ above average was chosen after testing 0.1 increments in SD from 1.5 to 2.0, which yielded same accuracy level across all SD thresholds (88.3\% correct 


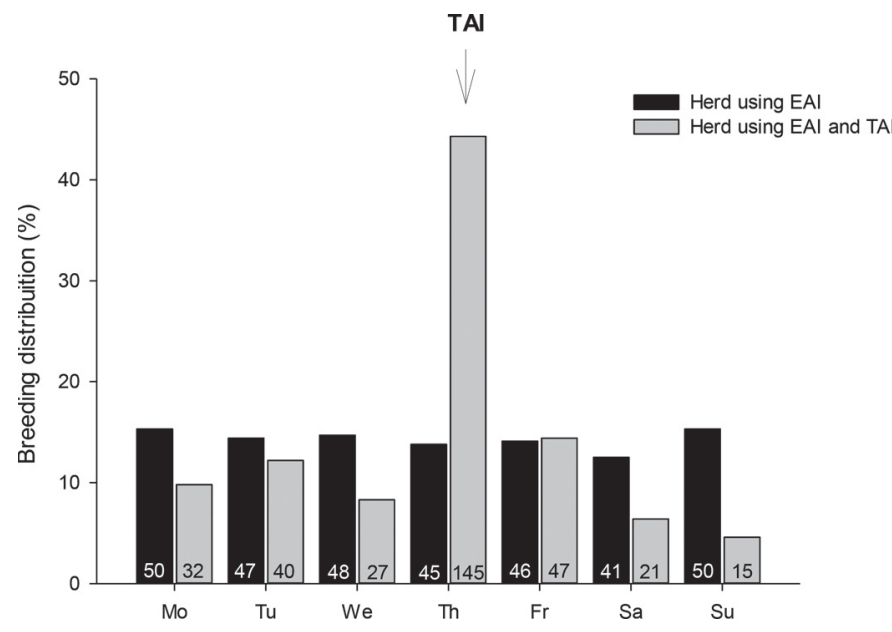

Figure 1. Breeding distribution by day of the week for a herd using estrus detection (EAI; black bars) exclusively and another herd (gray bars) combining both EAI and timed AI (TAI) in their reproductive program.

classifications of TAI breedings based on records from 10 herds with known breeding codes). In addition, the 2 SD tends to be rather strict in classifying breeding codes as TAI, but at the same time it avoids classifying EAI as TAI in case EAI happens on the same day as TAI, as commonly found in herds relying more on daily EAI.

The Proc HPMIXED of SAS for Windows (version 9.3, SAS Institute Inc., Cary, NC) took into account effects of state within US territory, farm, cow identification, AI month, AI year, times bred $(1,2,3$, or more), parity (1, 2, 3, or more), DIM at breeding (continuous), and service sire. Farm, service sire, and cow-within farm were included in the statistical model as random variables. This model was used independently for the 2 differing breeding codes (EAI vs. TAI), and service sire fertility rankings within each breeding code were done for sires with $>700$ breeding records $(n=94$ service sires) and again for sires with $>1,000$ breeding records
( $\mathrm{n}=56$ service sires) performed following both EAI and TAI. Pearson correlations were calculated using the PROC CORR of SAS. Kappa agreement index was calculated with the PROC FREQ of SAS, and greater weight in the kappa analysis was given to service sires with greater number of recorded breedings. Bartlett's test was used to compare variance for $\mathrm{P} / \mathrm{AI}$ rank difference following TAI and EAI in service sires with less than or more than 1,000 breeding records. Statistical significance in all analyses was assumed for $P$-values $<0.05$; and $P$-values between 0.05 and 0.10 were interpreted as tendencies.

The proposed method to classify the type of AI into TAI or EAI correctly identified $88.3 \%$ of the TAI and $90.6 \%$ of the EAI breedings in the test subset of 10 herds in which we had actual breeding codes available for analysis. Most classification disagreements occurred the day before the scheduled TAI date for those cows showing estrus prematurely but entered in the farm's computer still as bred to TAI, and also for cows bred in true estrus after 60 DIM, but that happened to occur on the same day of the TAI. Therefore, it is necessary to explore a more adequate methodology to classify AI records into TAI or EAI, but having breeding codes added to the national DHIA record system would be the ultimate solution to minimize misclassifications in nationwide breeding records. Despite that, P/AI for EAI and TAI did not differ $(P>0.10)$ and were $34.8 \%$ (range $=29.4 \%$ to $40.6 \%$ ) and $33.7 \%$ (range $=24.0 \%$ to $41.7 \%$ ), respectively. Pregnancy per AI according to data source and type of AI is shown in Table 1. The differences across data centers are remarkable in the proportion of TAI use as well as milk production level, and the fact that areas with greater milk production also appear to use TAI more frequently (Table 1).

One important aspect to consider in the current study is that we performed a retrospective analysis using uncontrolled breeding records from commercial dairies that had different breeding managements. Con-

Table 1. General overview and characteristics of the dairy herds included in the database used to classify breedings into AI after estrus (EAI) or timed AI (TAI) ${ }^{1}$

\begin{tabular}{lccccc}
\hline Data source $^{2}$ & Herds $(\mathrm{n})$ & \multirow{2}{*}{$305 \mathrm{ME}^{3}(\mathrm{~kg})$} & TAI $^{4}$ use $(\%)$ & ${\text { TAI-P } / \mathrm{AI}^{5}(\%, \mathrm{n})}^{\text {EAI-P } / \mathrm{AI}^{6}(\%, \mathrm{n})}$ \\
\hline AGS & 609 & 13,561 & 43.7 & $33.4(97,028)$ & $35.4(124,917)$ \\
ATA & 147 & 12,099 & 17.2 & $29.3(40,956)$ & $32.0(197,615)$ \\
DRMS & 1,431 & 12,911 & 29.5 & $33.7(117,232)$ & $34.0(279,791)$ \\
\hline
\end{tabular}

${ }^{1}$ Database was from three US data centers (AgSource, Agritech Analytics, and Data Records Management Services).

${ }^{2}$ AGS $=$ AgSource, ATA $=$ Agritech Analytics, DRMS $=$ Data Records Management System.

${ }^{3}$ Standardized 305-d milk production.

${ }^{4}$ Proportion of AI performed following an Ovsynch-like timed-AI program out of all AI.

${ }^{5}$ Pregnancy per AI $(\mathrm{P} / \mathrm{AI})$ for breedings performed in cows that received TAI.

${ }^{6}$ Pregnancy per AI (P/AI) for breedings performed in cows detected in estrus (EAI). 
sequently, it is possible that subpopulations of cows that were not detected in estrus and likely had lower fertility (i.e., anovular condition, lower body scores, and so on) ended up receiving TAI. Thus, caution should be used when comparing $\mathrm{P} / \mathrm{AI}$ results for EAI and TAI; nevertheless, our objective was to evaluate if some service sires would consistently deviate in terms of $\mathrm{P} / \mathrm{AI}$ rankings when used following EAI or TAI.

As shown in Figure 2, correlation between $\mathrm{P} / \mathrm{AI}$ rankings for same service sires used following EAI and TAI were $0.81(P<0.01$; for service sires with $>700$ breedings for each type of AI) and $0.84(P<0.01$; for service sires with $>1,000$ breedings). In addition, the weighted kappa agreement index between EAI and TAI rankings was 0.78 when considering sires with more than 700 breedings and 0.71 when taking into consideration sires with more than 1,000 breedings recorded per type of AI. Similar to the correlation analysis, the Kappa scores, although not perfect, also indicate that both service sire P/AI rankings have a high level of agreement. However, important changes were found in service sire $\mathrm{P} / \mathrm{AI}$ ranking to EAI and TAI for sires with less than 10,000 recorded AI as shown in Figure 3 . Thus, it appears that the type of breeding strategy (EAI or TAI) was associated with some changes in service sire $\mathrm{P} / \mathrm{AI}$ ranking, but it was also clear that ranking changes declined as number of breedings per service sire increased.

When we classified service sires into low, average and high fertility based on $\mathrm{P} / \mathrm{AI}$ to EAI, no evidence was found that TAI would improve P/AI in service sires with low EAI (Figure 4). The success in breeding somewhat early in relation to the time of ovulation appears to be limited by sperm lifespan in the uterine tract, and we hypothesized that a selected population of service sires having poor $\mathrm{P} / \mathrm{AI}$ to EAI would have improved $\mathrm{P} / \mathrm{AI}$ results when used following TAI programs. For example, Nadir et al. (1993) studied cows that were bred at approximately 6 to $16 \mathrm{~h}$ following the onset of estrus, and reported a great variation among bulls with respect to numbers of sperm cells reaching the ovum (Nadir et al., 1993), which may help explain the profound effect that semen quality from individual bulls may have on pregnancy results in the field (DeJarnette et al., 2008; Saacke, 2008; Sales et al., 2011). Thus, semen quality in frozen-thawed straws will essentially depend on the number of live sperm per semen dose and level of compensable and uncompensable defects (Saacke et al., 2000), and that will dictate the amount of time that sufficient sperm would remain viable in the uterine tract and capable of fertilizing the oocyte after ovulation occurs. Although we identified the use of TAI protocols based on the distribution of breed-
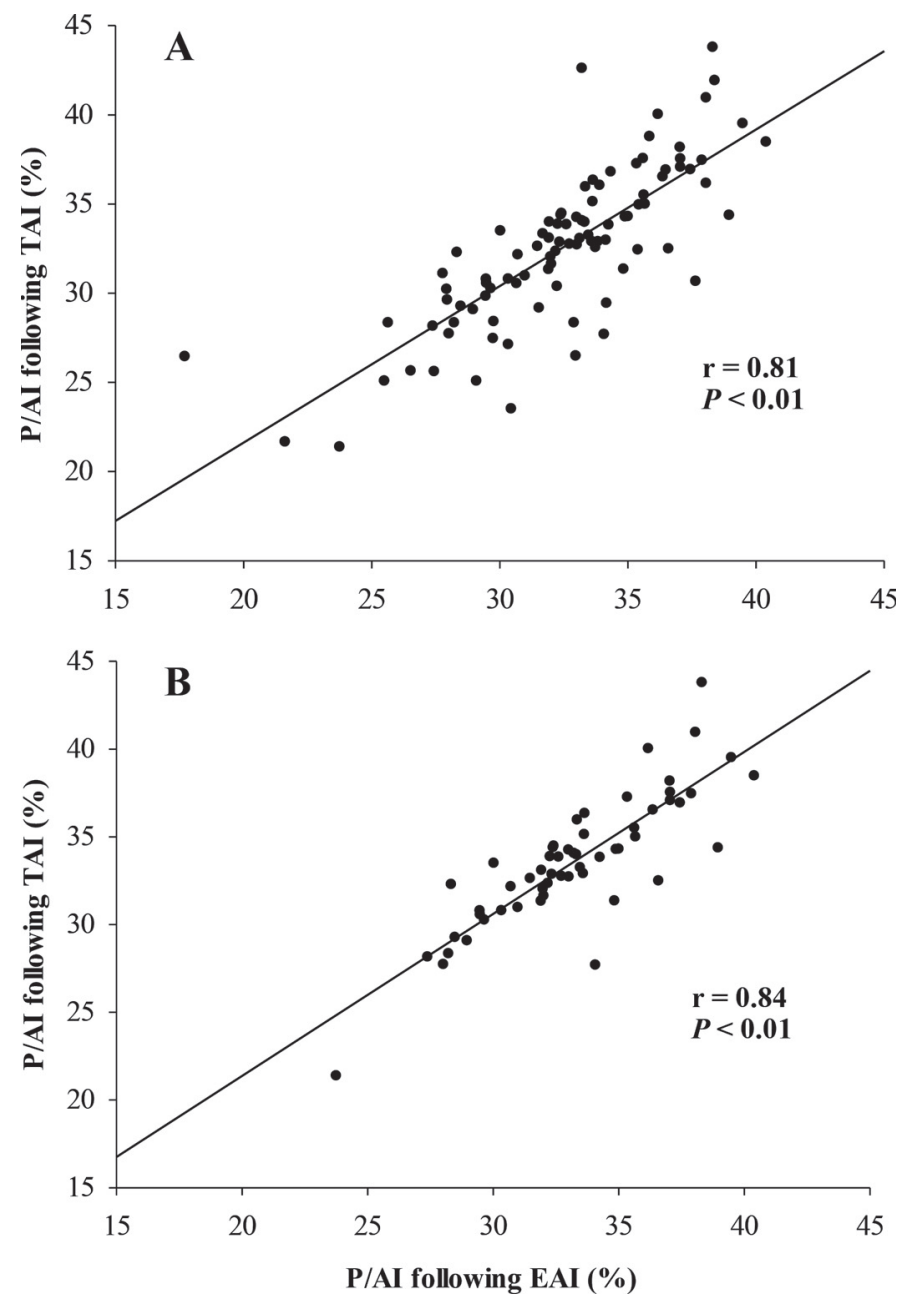

Figure 2. Correlation between pregnancy per AI (P/AI) from the same sires when AI was performed following estrus detection (EAI) or timed AI (TAI). Panel A: included sires $(\mathrm{n}=94)$ with at least 700 breeding records for each type of AI; panel B: included sires $(\mathrm{n}=56)$ with at least 1,000 breeding records for each type of AI.

ings performed at every day of the week within each herd, we did not have exact information on the type of synchronization of ovulation protocol used or when AI was performed after the last $\mathrm{GnRH}$ treatment used to induce ovulation. Still, breedings associated with TAI protocols likely had shorter and less variable intervals from AI to ovulation, mainly because the use of $\mathrm{GnRH}$ to induce ovulations should reduce the proportion of cows having late ovulations (Kaim et al., 2003). Interestingly though, when we considered only service sires with poor fertility following EAI breedings to evaluate whether TAI would improve P/AI results on those same service sires, we observed no evidence that the use of TAI would improve $\mathrm{P} / \mathrm{AI}$ in service sires underperforming following EAI (Figure 4). 


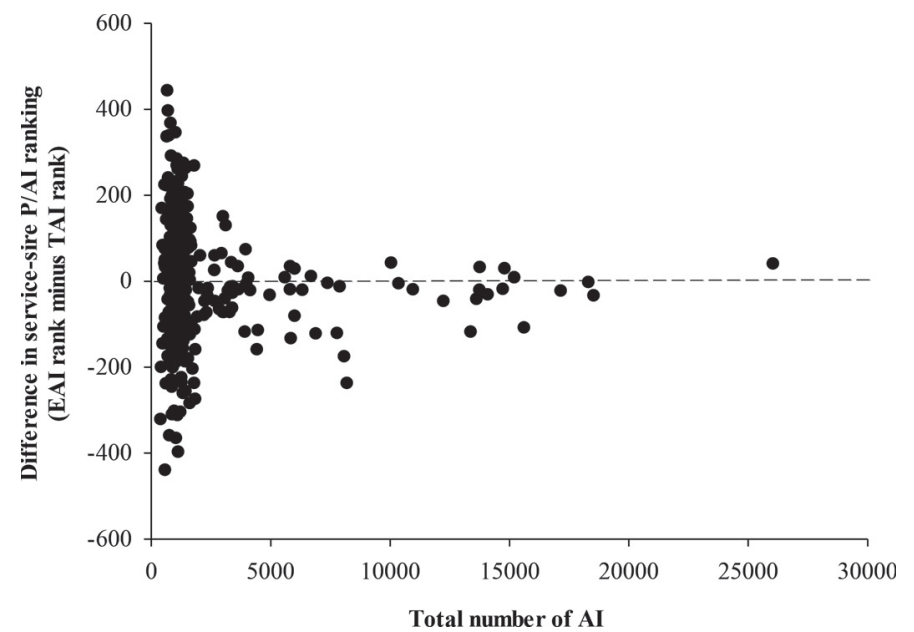

Figure 3. Difference in service sire pregnancy per AI (P/AI) ranking positions represented by estrus detection (EAI) rank minus timed AI (TAI) rank and according to total number of service records per service sire. Bartlett test comparing variances for service sires with $<1,000$ versus $>1,000$ AI records: $P<0.01$.

In conclusion, the type of breeding strategy (EAI or TAI) was associated with some changes in service sire P/AI ranking particularly for sires with less than 10,000 recorded breedings; but these changes in $\mathrm{P} / \mathrm{AI}$ ranking also obviously declined as number of breedings per service sire increases. Further studies with better control of the AI-to-ovulation intervals and randomizing service sires with different sperm characteristics need to be performed to more properly test for the

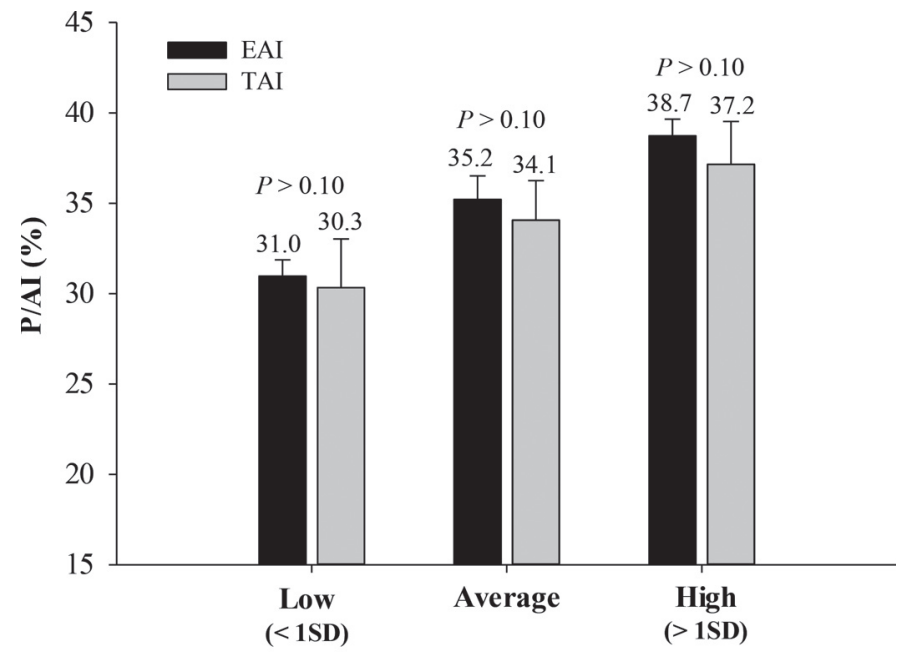

Figure 4. Pregnancy per AI (P/AI) following estrus detection (EAI) or timed AI (TAI), for sires classified into 3 fertility classes (low, average, and high) based only on EAI records. Sire fertility classes based only on data from EAI to evaluate whether TAI would improve $\mathrm{P} / \mathrm{AI}$ in low-performing sires. Data are presented as means $\pm \mathrm{SEM}$. presence of a significant variation across service sires in terms of $\mathrm{P} / \mathrm{AI}$ when used following EAI or TAI.

\section{ACKNOWLEDGMENTS}

The authors thank the National Dairy Herd Improvement Association (DHIA, Verona, WI) and Accelerated Genetics (Baraboo, WI) for providing the database and USDA Agriculture and Food Research Initiative (AFRI) Competitive Grant no. 2010-85122-20612 for supporting this research.

\section{REFERENCES}

Bloch, A., Y. Folman, M. Kaim, Z. Roth, R. Braw-Tal, and D. Wolfenson. 2006. Endocrine alterations associated with extended time interval between estrus and ovulation in high-yield dairy cows. J. Dairy Sci. 89:4694-4702.

Caraviello, D. Z., K. Weigel, P. Fricke, M. Wiltbank, M. Florent, N. Cook, K. Nordlund, N. Zwald, and C. Rawson. 2006. Survey of management practices on reproductive performance of dairy cattle on large US commercial farms. J. Dairy Sci. 89:4723-4735.

DeJarnette, J. M., R. L. Nebel, C. E. Marshall, J. F. Moreno, C. R. McCleary, and R. W. Lenz. 2008. Effect of sex-sorted sperm dosage on conception rates in Holstein heifers and lactating cows. J. Dairy Sci. 91:1778-1785.

Dransfield, M. B. G., R. L. Nebel, R. E. Pearson, and L. D. Warnick. 1998. Timing of insemination for dairy cows identified in estrus by a radiotelemetric estrus detection system. J. Dairy Sci. 81:1874-1882

Gosálvez, J., M. A. Ramirez, C. López-Fernández, F. Crespo, K. M. Evans, M. E. Kjelland, and J. F. Moreno. 2011. Sex-sorted bovine spermatozoa and DNA damage: II. Dynamic features. Theriogenology 75:206-211

Hernández-Cerón, J., L. Zarco, and V. Lima-Tamayo. 1993. Incidence of delayed ovulation in Holstein heifers and its effects on fertility and early luteal function. Theriogenology 40:1073-1081.

Hockey, C. D., J. M. Morton, S. T. Norman, and M. R. McGowan. 2010. Improved prediction of ovulation time may increase pregnancy rates to artificial insemination in lactating dairy cattle. Reprod. Domest. Anim. 45:e239-e248.

Kaim, M., A. Bloch, D. Wolfenson, R. Braw-Tal, M. Rosenberg, H. Voet, and Y. Folman. 2003. Effects of GnRH administered to cows at the onset of estrus on timing of ovulation, endocrine responses, and conception. J. Dairy Sci. 86:2012-2021.

MacMillan, K. L., and J. D. Watson. 1975. Fertility differences between groups of sires relative to the stage of oestrus at the time of insemination. Anim. Sci. 21:243-249.

Michaelis, I., E. Hasenpusch, and W. Heuwieser. 2013. Estrus detection in dairy cattle: Changes after the introduction of an automated activity monitoring system? Tierärztl Prax G Grosstiere Nutztiere 41:159-165.

Nadir, S., R. G. Saacke, J. Bame, J. Mullins, and S. Degelos. 1993 Effect of freezing semen and dosage of sperm on number of accessory sperm, fertility, and embryo quality in artificially inseminated cattle. J. Anim. Sci. 71:199-204.

Nebel, R. L., W. Walker, M. McGilliard, C. Allen, and G. Heckman. 1994. Timing of artificial insemination of dairy cows: Fixed time once daily versus morning and afternoon. J. Dairy Sci. 77:31853191.

Pursley, J. R., M. O. Mee, and M. C. Wiltbank. 1995. Synchronization of ovulation in dairy cows using $\mathrm{PGF}_{2 \alpha}$ and $\mathrm{GnRH}$. Theriogenology 44:915-923.

Pursley, J. R., R. W. Silcox, and M. C. Wiltbank. 1998. Effect of time of artificial insemination on pregnancy rates, calving rates, pregnancy loss, and gender ratio after synchronization of ovulation in lactating dairy cows. J. Dairy Sci. 81:2139-2144. 
Rankin, T. A., W. R. Smith, R. D. Shanks, and J. R. Lodge. 1992. Timing of insemination in dairy heifers. J. Dairy Sci. 75:2840-2845.

Roelofs, J. B., E. A. M. Graat, E. Mullaart, N. M. Soede, W. Voskamp-Harkema, and B. Kemp. 2006. Effects of insemination-ovulation interval on fertilization rates and embryo characteristics in dairy cattle. Theriogenology 66:2173-2181.

Saacke, R. G. 2008. Insemination factors related to timed AI in cattle. Theriogenology 70:479-484.

Saacke, R. G., J. C. Dalton, S. Nadir, R. L. Nebel, and J. H. Bame. 2000. Relationship of seminal traits and insemination time to fertilization rate and embryo quality. Anim. Reprod. Sci. 60-61:663677.

Sales, J. N. S., K. A. L. Neves, A. H. Souza, G. A. Crepaldi, R. V. Sala, M. Fosado, E. P. Campos, M. de Faria, M. F. Sa, and P. S. Baruselli. 2011. Timing of insemination and fertility in dairy and beef cattle receiving timed artificial insemination using sex-sorted sperm. Theriogenology 76:427-435.

Saumande, J., and P. Humblot. 2005. The variability in the interval between estrus and ovulation in cattle and its determinants. Anim. Reprod. Sci. 85:171-182.
Souza, A. H., P. D. Carvalho, R. D. Shaver, M. C. Wiltbank, and V. Cabrera. 2013. Epidemiology of synchronization programs for breeding management in US dairy herds. J. Dairy Sci. 96(Suppl. 1):288.

Souza, A. H., S. Viechnieski, F. A. Lima, F. F. Silva, R. Araújo, G. A. Bó, M. C. Wiltbank, and P. S. Baruselli. 2009. Effects of equine chorionic gonadotropin and type of ovulatory stimulus in a timedAI protocol on reproductive responses in dairy cows. Theriogenology $72: 10-21$.

Trimberger, G. W. 1948. Breeding efficiency in dairy cattle from artificial insemination at various intervals before and after ovulation. Nebraska Agric. Exp. Stn. Bull. 153:3-26.

Valenza, A., J. Giordano, G. Lopes Jr., L. Vincenti, M. Amundson, and P. Fricke. 2012. Assessment of an accelerometer system for detection of estrus and treatment with gonadotropin-releasing hormone at the time of insemination in lactating dairy cows. J. Dairy Sci. 95:7115-7127. 